\title{
Barriers to the Provision of Smoking Cessation Services Reported by Clinicians in Underserved Communities
}

\author{
Daniel S. Blumenthal, MD, MPH
}

Purpose: This qualitative study describes barriers to the provision of smoking cessation services among primary care providers serving medically underserved populations in the state of Georgia.

Methods: Eighty-two health care professionals, including clinicians, nurses, administrators, and support staff, participated in $\mathbf{1 0}$ focus groups. All sessions were audiotaped and transcribed. A line-by-line analysis of each transcript was conducted.

Results: Barriers were grouped into 5 major themes: lack of time, patient unreadiness to change, inadequate patient resources, inadequate provider resources, and inadequate cessation clinical skills. Within this framework, a number of barriers were identified that are of special importance when caring for the underserved. Examples included the tendency of patients to present in "crisis" rather than on an appointment basis; patients' inability to pay out-of-pocket expenses for drug therapy; patients' inability to take time from work for cessation services; limited prescribing authority for clinicians in certain settings; inadequate availability of patient education materials, especially non-English materials; and the need for additional training in smoking cessation for providers.

Conclusion: "Safety net" providers encounter barriers to providing smoking cessation services that are similar to barriers faced by clinicians serving more affluent and nonminority populations, but also encounter additional barriers that apply most particularly to the underserved. (J Am Board Fam Med 2007;20:272-279.)

Although the prevalence of smoking has declined steadily since the mid-1960s, approximately $20.9 \%$ of adults in the United States are current smokers (2004 data). ${ }^{1}$ The prevalence of smoking is highest among persons living below the poverty line (31.7\%), possessing a General Educational Development diploma (47.2\%), lacking access to medical care $(36 \%)$, or receiving Medicaid benefits (36\%) (2001 data). ${ }^{2,3}$

Clinicians have improved the rate of smoking cessation among their patients by increasing their

This article was externally peer reviewed.

Submitted 9 July 2006; revised 22 November 2006; accepted 27 November 2006.

From the Department of Community Health and Preventive Medicine, Morehouse School of Medicine, Atlanta, GA.

Funding: This study was supported by a grant from the Georgia Division of Public Health and Grant 5P20RR11104 from the National Center for Research Resources (a component of the National Institutes of Health), with additional support provided by Centers for Disease Control and Prevention Cooperative Agreement 5U48-DP000049 (Prevention Research Centers and Cancer Prevention and Control Research Network).

Conflict of interest: none declared.

Corresponding author: Daniel S. Blumenthal, MD, MPH, Morehouse School of Medicine, 720 Westview Drive SW, Atlanta, GA 30310 (E-mail: dblumenthal@msm.edu). counseling skills, incorporating reminders into practice systems, and offering pharmacotherapy. ${ }^{4-9}$ However, although physicians often advise their smoking patients to quit, they frequently fail to provide cessation assistance. Nationally, smoking counseling by physicians increased from 16\% of smokers' visits in 1991 to $29 \%$ in 1993 and then decreased to $21 \%$ by $1995 .{ }^{10}$ Women, ethnic minorities, and Medicaid and uninsured patients are less likely to receive appropriate cessation services, even although such services are effective among these groups. ${ }^{7,11-13}$

There are gaps in the literature on physicianidentified barriers to providing smoking cessation services. Some general information has been gathered on barriers identified by physicians to clinical practice guidelines. ${ }^{14,15}$ Such barriers include lack of awareness, lack of familiarity, disagreement, lack of self-efficacy, and inability to overcome the inertia of previous practice. A study from the 1980s showed that medical students had low confidence in the ability of physicians to provide smoking cessation services. ${ }^{16}$ Several surveys explore barriers to smoking cessation services among physicians who care for adolescents. ${ }^{17-19}$ Surveys have also 


\begin{tabular}{|c|c|c|c|c|c|c|}
\hline Focus Group & Physician & Midlevel Provider* & Nurse & Administrator & Other† & Total \\
\hline 1 & 3 & 0 & 2 & 0 & 0 & 5 \\
\hline 2 & 1 & 3 & 0 & 1 & 0 & 5 \\
\hline 3 & 2 & 1 & 1 & 0 & 1 & 5 \\
\hline 4 & 3 & 3 & 3 & 1 & 0 & 10 \\
\hline 5 & 1 & 4 & 2 & 0 & 0 & 7 \\
\hline 6 & 2 & 0 & 0 & 3 & 2 & 7 \\
\hline 7 & 11 & 0 & 0 & 0 & 0 & 11 \\
\hline 8 & 3 & 1 & 7 & 0 & 1 & 12 \\
\hline 9 & 6 & 0 & 1 & 0 & 0 & 7 \\
\hline 10 & 2 & 2 & 5 & 2 & 2 & 13 \\
\hline Total & 34 & 14 & 21 & 7 & 6 & 82 \\
\hline
\end{tabular}

* Midlevel provider includes nurse practitioner and physician assistant.

† Other includes registered dietician, pharmacist, social worker, or medical student.

been administered to emergency physicians, ${ }^{20}$ dentists, ${ }^{21}$ and physicians caring primarily for middleclass and insured patients. ${ }^{2-24}$ In addition, there is a robust foreign literature. ${ }^{25-28}$ However, there is only 1 study of the views of African-American physicians, ${ }^{29}$ none focusing on physicians caring for low-income patients, and none using primarily qualitative methods.

This last gap- the absence of studies using qualitative methods-represents an important shortcoming in the smoking cessation literature. Most of the medical literature relies on quantitative methods in which results are expressed as numbers or rates. However, in qualitative research, results are presented descriptively, and they are particularly valuable in helping to answer "how" and "why" questions and in shedding light on attitudes, behaviors, perception, and culture. ${ }^{30}$ Qualitative research on the topic of smoking cessation, then, can help the investigator see the issue through the eyes of clinicians in a way that survey research could not.

It is important to understand the obstacles facing physicians serving the underserved, because this subpopulation has the highest rates of smokingrelated illnesses and, as pointed out above, has the highest smoking rates. The underserved population consists in large part of people who are uninsured or underinsured, minorities, poor, and/or poorly educated. They are often cared for in public-sector facilities such as community health centers, public hospitals, and health department clinics. It is reasonable to hypothesize that clinicians caring for the underserved face special barriers or challenges in delivering smoking cessation services to their patients.

We conducted a series of focus groups to gain insight into clinical cessation experiences and barriers to cessation services among community-based clinicians that serve minority or low-income populations in Georgia. The focus groups also provided an opportunity to identify the availability and accessibility of community services and resources for smoking cessation.

\section{Methods}

The study was approved by the Morehouse School of Medicine Institutional Review Board. Over a 7-month period, we conducted 10 focus groups among clinicians and support staff serving lowincome and minority patients from urban and rural medically underserved communities in Georgia. Each focus group comprised 5 to 12 participants $(\mathrm{N}=82)$, including physicians (34), physician assistants and nurse practitioners (14), nurses (21), dietitians (2), administrators (7), a social worker, a pharmacist, and 2 medical students (Table 1). The clinical specialties represented included family medicine, internal medicine, preventive medicine, and pediatrics. The racial distribution of the participants was $52 \%$ black, $27 \%$ white, and $1 \%$ Asian/ Pacific Islander; $20 \%$ elected not to identify their race or ethnicity. Of the 10 focus groups, 5 were conducted in metro Atlanta (50 participants) and 5 in rural areas of Georgia (32 participants). 
Table 2. Practice Settings and Health Care Professionals Participating in Focus Groups

\begin{tabular}{|c|c|c|c|c|c|c|}
\hline Type & $\begin{array}{l}\text { Private } \\
\text { Practice }\end{array}$ & $\begin{array}{l}\text { Community } \\
\text { Health Centers }\end{array}$ & $\begin{array}{c}\text { Health } \\
\text { Department }\end{array}$ & $\begin{array}{l}\text { Morehouse School } \\
\text { of Medicine }\end{array}$ & $\begin{array}{c}\text { County Hospital } \\
\text { Neighborhood Health Center }\end{array}$ & Total \\
\hline Physician & 3 & 8 & 1 & 19 & 3 & 34 \\
\hline Physician assistant & 0 & 7 & 0 & 0 & 0 & 7 \\
\hline Nurse practitioner & 0 & 3 & 3 & 0 & 1 & 7 \\
\hline Nurses & 2 & 10 & 1 & 1 & 7 & 21 \\
\hline Pharmacist & 0 & 1 & 0 & 0 & 0 & 1 \\
\hline Social worker & 0 & 1 & 0 & 0 & 0 & 1 \\
\hline Nutritionist & 0 & 1 & 0 & 0 & 1 & 2 \\
\hline Administration & 0 & 3 & 1 & 3 & 0 & 7 \\
\hline Student & 0 & 0 & 0 & 2 & 0 & 2 \\
\hline Total & 5 & 34 & 6 & 25 & 12 & 82 \\
\hline
\end{tabular}

The project's recruitment plan called for focus group participants to be recruited from a diverse group of settings that served low-income and minority patients. There was no specific target number for each type of participant or each type of setting. Facilities from which participants were recruited included federally funded community health centers, Morehouse School of Medicine (a historically black medical school), a county hospital neighborhood health center, a local public health department, and the private practices of AfricanAmerican physicians (Table 2). Physicians received a $\$ 100$ honorarium for participation, and midlevel staff and nurses received a $\$ 50$ honorarium. Meals were also provided.

Each focus group lasted 60 to 90 minutes. The study coordinator, a family physician, facilitated each session using open-ended questions contained in an interview guide approved by the Morehouse School of Medicine Institutional Review Board. Questions included the following: "What approaches to tobacco cessation have you used?" "What barriers do you experience in attempting to implement tobacco control?" "Among the patients that you have provided with tobacco cessation counseling or treatment, what barriers do they encounter when using these services?" Each focus group session was audiotaped and subsequently transcribed.

Computer programs are often used in the analysis of qualitative research, but were not used in this study. To analyze the transcripts, the focus group facilitator read them line-by-line and identified main themes and patterns of responses. Themes were identified based on recurring comments in multiple focus group discussions or com- ments that resulted in intense discussion in a particular focus group interview. Participants' quotes that were related to a theme were grouped. The transcripts were also reviewed by a second independent reviewer to assess the accuracy and completeness of theme identification. Differences were reconciled by discussion. Rural-urban subgroup analyses were done according to the location of the focus group, but we were unable to consider racial subgroup analyses because most of the focus groups were multiracial and the race/ethnicity of individual participants was not recorded.

\section{Results}

Five major themes were identified as barriers to the provision of smoking cessation services:

- Lack of time

- Patient unreadiness to change

- Inadequate patient resources

- Inadequate provider resources

- Inadequate cessation clinical skills

\section{Lack of Time}

In each group, participants identified limited time available during a patient encounter as a major barrier to the provision of cessation services. Clinicians indicated that they usually addressed multiple problems during an office visit, limiting the time available to provide cessation interventions. A comment by a clinician illustrates the participants' concern: "Most of our patients are walk-ins, not scheduled patients. They come to you in some type of crisis. And as you take the history, you discover 
that they do smoke, but usually at that time you're in a crisis and you end up spending [time] with that crisis and you don't have as much time for prevention." A similar comment that reflects the same issue: "Time is one of those issues that we have when we [are] seeing patients ... and sometimes when we get into counseling with patients, it takes a lot longer to do that [counseling]." Time limitations sometimes interacted with other barriers, such as language and culture: “. . . by the time I call in my translator to repeat everything I've said, I've turned a 5-minute [talk] into a 14- to 15 -minute talk.”

\section{Patient Unreadiness to Change}

Participants reported that engaging patients in cessation activities was difficult when patients were not ready to quit. One clinician stated, “... but in the time that I have been at community health centers, smoking cessation has been a frustrating thing. They [patients] seem to come in for acute things, not wanting to manage chronic problems. Many of them are not seeing tobacco use as a problem." A private practitioner stated, "The biggest barrier I've gotten from patients is they enjoy smoking. So they don't want to quit. So we work on that. With the pharmaceutical therapy, they tell me that it just makes the cigarettes taste bad. So they quit taking the pills." This perspective was consistent with the fact that clinicians often did not pursue cessation among their smoking patients until the smokers requested assistance in quitting.

\section{Inadequate Patient Resources}

Participants reported that health insurance did not necessarily aid adherence to (compliance with) drug therapy. For instance, a nurse reported difficulty in getting the patients' health care plans to provide coverage for cessation drug therapy. "I find it very, very frustrating because the patient is ready, they're motivated, they want to do it [quit], but the insurance company says 'No, we can't do that for you.'”

Out-of-pocket expenses associated with drug therapy adversely affected patient adherence. For instance: "I have a lot of patients that either have no income or are low income, and so if it's something they have to purchase, they're not going to get it, even if it's the over-the-counter stuff. They're not going to buy it. They're just not going to spend the money."

Participants reported that nonadherence to follow-up office appointments was another common barrier in low-income patients. According to one clinician, “. . . they work jobs where they don't have any benefits and they don't have any time off. And they need to be ill when they come in to see the doctor, and so I think a lot of time the patient is not being insincere when they don't come back. They really can't take off any more time to come back to address that issue [smoking cessation]."

\section{Inadequate Provider Resources}

Providers reported limited access to pharmacotherapy. Except for 1 center that had secured a grant to provide nicotine replacement therapy, the practices were not able to dispense such therapy from their offices. One clinician reported: "We have to send people to the [public] mental health clinic. So I think that's a big barrier for us. I think if we had Zyban [bupropion] available here, we could get a lot of people at least to try it."

Among providers who practiced in urban organizations that offered cessation services at a cessation specialty clinic, only specialty clinic providers had prescribing privileges for drugs to aid tobacco use cessation. Clinicians in the general clinic perceived this as a barrier.

Providers also reported limited availability of patient education resources and personnel. An illustrative comment was, "I don't have any handouts that I consistently give. So if they're young and I have some information from the American Lung Association, I may give that out, but nothing on a consistent basis, which is what we need." Another participant conveyed frustration with limited resources with the following comment: "If the state would allocate money to the community health centers to set up smoking cessation programs, then it would be beneficial to us. We could, if we had the funds available, hire 1 or 2 people that would do nothing but smoking cessation programs. .."

The participants' awareness of the state-sponsored telephone Quit Line varied, and even among those that were familiar with that resource, few reported routinely using it. Several support staff found direct communication with the Quit Line to be frustrating. One participant reported: "Mr. X [a physician assistant] had gotten some [Quit Line literature], and I think Dr. Y had gotten some, but they wouldn't send any to me, even although I said I was a health educator for 7 community health centers."

Regardless of the practice setting, participants provided services to a diverse racial or ethnic population and reported a need for educational mate- 
rials in Spanish for Hispanic patients to overcome the language barrier. One clinician's comment illustrates the shortage: "I was looking at your Hispanic material because of the growing number that we have of patients who are Latino. We need more information and cultural specific information to deal with smoking cessation." One clinic was in need of patient education materials in French because the providers' clientele included immigrants from francophone Africa.

\section{Clinical Skills}

When asked about the need for additional training, clinicians agreed that they would benefit from the opportunity to receive cessation training. A comment by 1 clinician illustrates the concern: "My medical school did reinforce tobacco cessation and its importance. I feel strong with that but of course, there's always something new. Wellbutrin was not available at the time of my medical school training but became so in my internship and probably something is available now for different techniques of cessation. So I do think I'd benefit from it." Another clinician stated: "... a lot of us have basic knowledge. However, that does not necessarily translate into tools that are effective and sufficient. So our main thing is when we've got 40 to 50 patients a day, how in the world are we going to get this done and to get this done effectively? So yes, training is necessary."

\section{Discussion}

Barriers to the provision of cessation services among clinicians serving medically underserved communities included the following themes, which in some aspects were found to be peculiar to providers caring for the underserved:

\section{Lack of Time}

This is a factor for nearly all clinicians, regardless of their patient population. However, it may manifest in special ways for clinicians caring for the underserved-for instance, if the clinician must communicate with the patient through a translator.

\section{Patient Unreadiness to Change}

Clinicians felt that their low-income smoking patients had less interest in quitting smoking than more affluent smokers, an impression that is consistent with higher rates of tobacco use among this population. ${ }^{2,3}$ They also felt that their low-income patients were more likely than persons with higher incomes to present only when in distress, a circumstance in which it is difficult to address tobacco use, but we do not have data to support this impression.

\section{Inadequate Resources Available to Providers}

Providers cited inadequate access to a number of resources needed to provide cessation services for the underserved, including pharmaceuticals for low-income patients and those without prescription drug coverage. Clinicians felt that appropriate patient education materials were in short supply, especially Spanish-language materials, and many also felt that they had inadequate access to information about the Quit Line. However, both of these "shortages" may represent inadequate efforts by the clinicians to obtain the needed materials and information. Whether real shortages or only apparent ones, they represent barriers especially relevant to the underserved, who are often poorly educated and/or nonfluent in English.

\section{Inadequate Resources Available to Patients}

Barriers that apply particularly to the underserved are especially common in this area. The barriers include an inability to pay for pharmacotherapy because of low income combined with inadequate or no health insurance, and a tendency to miss follow-up appointments, perhaps because many seek health care only when acutely ill.

\section{Providers' Inadequate Cessation Clinical Skills}

When asked, many clinicians acknowledged their shortcomings in this area. This is a barrier that would apply to any smoking patient, but in the case of patients from many underserved groups, there is arguably an additional hurdle to clear-the need for a modicum of "cultural competence" ${ }^{31}$ (“. . . a set of congruent behaviors, attitudes, and policies that come together in a system, agency, or among professionals that enables effective work in crosscultural situations"). ${ }^{32}$ This was not made explicit by the professionals in our focus groups, but was suggested by the frequent references to the need for translators, Spanish-language educational materials, and the like.

\section{General Observations}

Patient volume, scheduling patterns, and multiple medical complaints were often responsible for ex- 
hausting the limited time available for patient care. Except for identification of need for additional tobacco cessation training, clinicians generally considered that cessation service barriers were due to factors external to members of the health care team. Hence, although the clinicians' perspective tended to be self-exonerating, one might argue that they could have done more to overcome the external barriers-for instance, by making more of an effort to obtain information about the Quit Line, by obtaining Spanish-language patient education materials, or by scheduling slightly longer encounters for smoking patients.

High patient volumes and the complexity of patients' health problems were cited as time-limiting factors. Our results are consistent with previous literature that reports that preventive services and educational counseling are provided less often in high patient volume settings. ${ }^{33,34}$ However, the US Public Health Service Guideline on Treating Tobacco Use and Dependence ${ }^{38}$ recommends asking all patients whether they use tobacco and points out that even a brief intervention can have an important impact on tobacco use.

We found that scheduling systems that accommodated patients on a walk-in basis reduced the opportunity for clinicians to engage in cessation counseling. The lower prevalence of cessation services during acute care visits has been reported among other clinicians in private practice ${ }^{35}$ and community health centers. ${ }^{7}$ However, preserving the opportunity to be seen on a walk-in basis may be essential in a facility serving low-income patients.

Language has emerged as a barrier to the provision of cessation services by African-American physicians, a phenomenon not noted in the previous study that examined smoking cessation counseling in this group of clinicians. ${ }^{30}$ This underscores the need for all physicians and facilities serving patients from diverse cultures to seek culturally and linguistically appropriate patient education materials.

Smoking cessation skills are not taught widely or well in medical school. ${ }^{36,37}$ However, our group of clinicians did not cite their own lack of skills prominently among the barriers to providing cessation services in their practices. Rather, they generally had to be prompted on this point, and even then noted that their skills were lacking primarily in relation to the other challenges they faced, such as lack of time in which to provide counseling and keeping up with recent developments in the field.
Preventive services in general are widely underutilized in primary care; it is virtually impossible to provide all recommended preventive services to all patients in patient encounters of reasonable length. ${ }^{39}$ Nearly all clinicians must address the barrier of limited time if they are to offer preventive services-especially those that involve counseling-to their patients. Moreover, as the current study demonstrates, clinicians caring for the underserved face a number of additional barriers. It is, therefore, important to prioritize and choose those services that produce the greatest "return on investment." Tobacco-use screening and brief intervention has been shown repeatedly to be one of the top 2 preventive services that can be offered to adults, considering both clinically preventable burden of disease and cost effectiveness. ${ }^{40,41}$ Hence, even when facing constrained resources, reluctant patients, and other barriers, clinicians should make an effort to deliver this service. In addition, institutions serving the underserved (such as community health centers and public hospitals) should review their policies and procedures and remove any systemic barriers to providing smoking cessation services.

This qualitative study captured experiences peculiar to our community of interest. We identified underutilized services such as specialty cessation clinics and telephone Quit Lines. Identification of these gaps can provide direction for the reallocation of resources to provide better care. For instance, we were able to show that, in the facilities we studied, the concentration of cessation services in specialty clinics had the unintended consequence of decreasing access to these services, especially among low-income patients who are unlikely to forfeit a day's pay to keep an appointment to such a clinic.

Similarly, improved knowledge of the Quit Line and how best to use its services on the part of health care teams could result in increased referrals to this resource. There are substantial advantages of telephone Quit Lines for low-income populations: they are free; access is not dependent on transportation or child care services; the hours are flexible and, therefore, accommodate work schedules; they provide private individualized assistance; and one need only have access to a phone during the Quit Line's hours of operation (8 AM to midnight, Monday through Saturday, in Georgia).

A strength of this study is the heterogeneity of focus group participants that allowed the participants to examine cessation service barriers from 
multiple professional and organizational perspectives. By conducting focus groups among professionals in diverse geographic and clinical settings, we were able to identify regional variations associated with access to cessation services. For instance, rural participants had less access than Atlanta-area participants to resources such as cessation clinics (although, as already noted, the presence of a cessation clinic was not necessarily regarded as an advantage by providers in the general clinic).

As in any focus group study, the participants were a small sample of nonrandomly selected subjects, so their responses may not be representative of clinicians generally. However, the purpose of a qualitative study such as this is not to generate generalizable findings, but to examine responses in depth and to generate new hypotheses. For instance, one might hypothesize that enabling primary care physicians in community health centers to prescribe pharmacotherapy for smoking cessation-rather than referring patients to a specialty clinic or mental health center-would increase patients' use of such therapy and their rates of smoking cessation. This hypothesis could then be tested by instituting this policy change at a set of community health centers (or a subset of community health centers, using an intervention/comparison group design) and measuring the rate at which prescriptions were filled and the rate at which patients were abstinent of tobacco 6 or more months after their initial quit attempt.

Our focus group participants were primarily public sector clinicians; only $5 \%$ of the participants were in private practice. This was due to our emphasis on clinicians practicing in underserved communities. Because we recruited primarily from sites that specialized in caring for the underserved, this imbalance was expected. However, a consistency of themes such as time constraints, limited patient treatment compliance, and limited access to resources occurred across the groups and were reported by both public- and private-sector participants.

\section{Conclusions}

Clinicians serving the underserved encounter barriers to providing smoking cessation services that are similar to those serving more affluent and nonminority populations but face additional barriers that apply most particularly to the underserved. For instance, it is important for such clinicians to recall that many low-income patients will not surrender a day's pay (or a job) to keep a follow-up appointment; hence, one should not miss opportunities to address smoking cessation at any visit. Practitioners serving non-English speaking minorities may need to hire bilingual staff or interpreters. Those serving patients from any minority group may need to seek appropriately tailored materials; materials tailored to Hispanic and African-American patients are available at http://smokefree.gov. Quit Lines are appropriate for most smokers seeking to quit, but may be particularly appropriate for low-income patients (in Georgia and many other states, a Spanishlanguage Quit Line is available). In some settings, it may be important to seek new strategies to increase access to pharmacotherapy.

I thank Mary Frazier, MD, MPH, who is currently on the faculty at Indiana University-Purdue University at Indianapolis, for her work on this project. At the time of this study, Dr. Frazier was on the faculty of the Morehouse School of Medicine, Atlanta, GA.

\section{References}

1. National Center for Health Statistics: Early Release of Selected Estimates Based on Data from the $2004 \mathrm{Na}$ tional Health Interview Survey. Available from: www. cdc.gov/nchs/about/major/nhis/released200506.htm\#88.

2. Centers for Disease Control and Prevention. Cigarette smoking among adults-United States, 2001. MMWR 2003;52:953-6.

3. Centers for Disease Control and Prevention. Health risk factor surveys of commercial plan- and Medicaid-enrolled members of health-maintenance organizations, Michigan, 1995. MMWR 1997;46:923-6.

4. Ahluwalia JS, Harris KJ, Catley D, Okuyemi KS, Mayo MS. Sustained release bupropion for smoking cessation in African Americans: a randomized control trial. JAMA 2002;288:468-74.

5. Fiore MC. Session I AHCPR smoking cessation guideline: a fundamental review. Tobacco Control 1997;6:S3-S22.

6. Ahluwalia JS, Gibson SA, Kenney RE, Wallace DD, Resnicow K. Smoking status as a sign. J Gen Intern Med 1999;14:402-8.

7. DePue JD, Goldstein MG, Schilling A, et al. Dissemination of the AHCRP clinical practice guideline in community health centres. Tobacco Control 2002;11:329-35.

8. Katz DA, Muehlenbruch DR, Brown RB, Fiore MC, Baker TB. Effectiveness of a clinic-based strategy for implementing the AHRQ smoking cessation guideline in primary care. Prev Med 2002;35:293-302.

9. Goldstein MG, Niaura R, Willey C, et al. An academic detailing intervention to disseminate physi- 
cian-delivered smoking cessation counseling: smoking cessation outcomes of the physicians counseling smokers' project. Prev Med 2003;36:185-96.

10. Thorndike AN, Rigotti NA, Stafford RS, Singer DE. National patterns in the treatment of smokers by physicians. JAMA 1998;279:604-8.

11. Report of the Surgeon General on Tobacco Use Among US Racial/Ethnic Minority Groups. Washington DC: US Department of Health and Human Services; 1998.

12. Schauffler HH, Mordavsky JK, McMenamin S. Adoption of the AHCRP clinical practice guideline for smoking cessations: a survey of California's HMOs. Am J Prev Med 2001;21:153-61.

13. Burns ME, Fiore MC. Under-use of tobacco dependence treatment among Wisconsin's fee-for-service Medicaid recipients. Wis Med J 2001;100:54-8.

14. Cabana MD, Rand CS, Powe NR, et al. Why don't physicians follow clinical practice guidelines? A framework for improvement. JAMA 1999;282:1458-65.

15. Tunis SR, Hayward RS, Wilson MC, et al. Internists' attitudes about clinical practice guidelines. Ann Intern Med 1994;120:965-63.

16. Scott CS, Neighbor WE. Preventive care attitudes of medical students. Soc Sci Med 1985;21:299-305.

17. Zapka JG, Fletcher K, Pbert L, et al. The perceptions and practices of pediatricians: tobacco intervention. Pediatrics 1999;103:e65.

18. Frankowski BL, Weaver SO, Secker-Walker RH. Advising parents to stop smoking: pediatricians' and parents' attitudes. Pediatrics 1993;91:296-300.

19. Kaplan CP, Perez-Stable EJ, Fuentes-Afflick E, et al. Smoking cessation counseling with young patients: the practices of family physicians and pediatricians. Arch Pediatr Adolesc Med 2004;158:83-90.

20. Prochazka A, Koziol-McLain J, Tomlinson D, Lowenstein SR. Smoking cessation counseling by emergency physicians: opinions, knowledge, and training needs. Acad Emerg Med 1995;2:211-6.

21. Simoyan OM, Badner VM, Freeman KD. Tobacco cessation services in dental offices. Are we doing all we can? N Y State Dent J 2002;68:34-40.

22. McIlvain HE, Backer EL, Crabtree BF, Lacy N. Physician attitudes and the use of office-based activities for tobacco control. Fam Med 2002;34:114-9.

23. Spitz MR, Chamberlain RM, Sider JG, Fueger JJ. Cancer prevention practices among Texas primary care physicians. J Cancer Ed 1992;7:55-60.

24. Fortmann SP, Sallis JF, Magnus PM, Farquhar JW. Attitudes and practices of physicians regarding hypertension and smoking: The Stanford Five City Project. Prev Med 1985;14:70-80.

25. Bauld L, Coleman T, Adams C, Pound E, Ferguson J. Delivering the English smoking treatment services. Addiction 2005;100(Suppl 2):19-27.

26. Twardella D, Brenner H. Lack of training as a central barrier to the promotion of smoking cessation: a survey among general practitioners in Germany. Eur J Public Health 2005; 15:140-5.

27. Mowat DL, Mecredy D, Lee F, Hajela R, Wilson R. Family physicians and smoking cessation. Survey of practices, opinions, and barriers. Can Fam Physician 1996;42:1946-51.

28. Helgason AR, Lund KE. General practitioners' perceived barriers to smoking cessation-results from four Nordic countries. Scand J Public Health 2002; 30:141-7.

29. Berman BA, Yancey AK, Bashani R, Grosser SC, Staveren A, Williams RA, Lee D. African-American physicians and smoking cessation counseling. J Nat Medical Assoc 1997;89:534-42.

30. Steckler A: Foreword. In Qualitative Methods in Public Health: A Field Guide for Applied Research. Ulin P, Robinson ET, Tolley EE, editors. San Francisco, CA: Jossey-Bass; 2004. p. xiii.

31. Kripalani S, Bussey-Jones J, Katz MG, Genao I. A prescription for cultural competence in medical education. J Gen Intern Med 2006;21:1116-20.

32. Teaching Cultural Competence In Health Care: A Review Of Current Concepts, Policies And Practices. Office of Minority Health, US Department of Health and Human Services Contract 282-98-0029 Task Order No. 41 Task 2: Synthesis Report March 12, 2002.

33. Zyzanski SJ, Strange KC, Langa D, Flocke SA. Trade-offs in high-volume primary care practice. J Fam Pract 1998;46:397-402.

34. Strange KC, Flock SA, Goodwin MA. Opportunistic preventive services delivery: are time limitations and patient satisfaction barriers? J Fam Pract 1998;46: 419-24.

35. Jaen CR, McIvain H, Pol L, et al. Tailoring tobacco counseling to the competing demands in the clinical encounter. J Fam Pract 2001;50:859-63.

36. Spangler JG, George G, Foley KL, Crandall SJ. Tobacco intervention training: current efforts and gaps in US medical schools. JAMA 2002;288:1102-9.

37. Geller AC, Zapka J, Brooks KR, et al. Prevention and Cessation Education Consortium: Tobacco control competencies for US medical students. Am J Public Health 2005;95:950-5.

38. Fiore MC, Bailey WC, Cohen SJ, et al. Treating Tobacco Use and Dependence. Clinical Practice Guideline. Rockville, MD: US Department of Health and Human Services, Public Health Service; June 2000.

39. Yarnall KS, Pollak KI, Ostbye T, Krause KM, Michener JL. Primary care: is there enough time for prevention? Am J Pub Health 2003;93:635-41.

40. Coffield AB, Maciosek, MV, McGinnis, JM, et al. Priorities among clinical preventive services. Am J Prev Med 2001;21:1-9.

41. Maciosek, MV, Coffield AB, Edwards MN, et al. Priorities among effective clinical preventive services: results of a systematic review and analysis. Am J Prev Med 2006;31:52-61. 